\title{
Analytical Solution for Optimal Mass Flow Rate in Primary Circuit of Ground-Coupled Heat Pump Systems
}

Damien Picard

\section{ABSTRACT}

Ground source heat pump (GSHP) systems extract heat or cold from the ground by circulating a heat carrier fluid (HCF) in a ground heat exchanger and inject this energy in buildings. This paper shows that there exists an optimal HCF flow rate which minimizes the energy use of such systems. The paper proposes an analytical solution for the optimal flow rate as a function of measurable variables, system parameters and data that can easily be derived from manufacturer data sheets. The analytical solution is validated using a detailed simulation model representing an existing GSHP system of 99 boreholes with a depth of $30 m$.

\section{INTRODUCTION}

Ground source heat pump (GSHP) systems extract heat or cold from the ground by circulating a heat carrier fluid (HCF) in a ground heat exchanger and inject this energy in buildings. Despite relatively high investment costs and thanks to their high energy efficiency, GSHP systems have proven their economic viability with about $10^{5}$ units sold every year in Europe between 2005 and 2013 (Nowak, Jaganjacova, \& Westring, 2014). Numerous studies and tools have been proposed to optimize the design of GSHPs in order to reduce the investment costs. Only a few of these studies propose (optimal) control strategies for the mass flow rate in the installation, while ASHRAE (2007) reports that pump energy represent 4 to $21 \%$ of the total energy demand of GSHP systems. This section firstly summarizes the findings from the literature about optimal flow in (ground source) heat pump systems and secondly, it describes the current paper objective and structure.

To the best authors' knowledge, Li and Lai (2013) were the first and only authors who proposed an analytical solution for optimal HCF flow rate and for optimal borehole length. Li and Lai applied an entropy minimization technique to a ground heat exchanger with single U-tube but without considering the heat pump. In their case, an optimal flow rate exists due to 1) a rising entropy generation from pressure drops when the flow rate increases and 2) a decreasing entropy generation due to smaller ground and HCF temperature differences when the flow rate increases. A major drawback of their method is that the analysis does not include the heat pump performance which depends on the HCF flow rate and temperature, while it plays a crucial role in the system performance. Furthermore, an entropy optimum does not necessarily coincide with an energy or economic optimum since entropy generated due to pressure drops has a different energetic and economic value than entropy generated due to heat transfer.

An energy optimization of the air flow rate in heat pump systems was proposed by Granryd (2010) for an air-to-air system. The author found an analytical solution that maximizes the $\mathrm{COP}_{2}{ }^{1}$ by using

\footnotetext{
${ }^{1}$ The coefficient of performance $2\left(\mathrm{COP}_{2}\right)$ is defined as the delivered useful energy (the condenser heat to the sink) divided by the electrical power use of the heat pump compressor and its fan or pump at both the source and sink sides. 
simple (empirical) correlations to express 1) the heat transfer and the pressure drop in the heat pump heat exchangers and, 2) the heat pump thermal power $\left(\dot{Q}_{c o n d}\right)$, as a function of the air velocity in the condenser and evaporator. The maximum $\mathrm{COP}_{2}$ is then obtained by setting its derivative towards the air velocity to zero. A $\mathrm{COP}_{2}$ optimum exists due to the increase of the heat pump $\mathrm{COP}_{1}$ and the increase of pressure losses for increasing air flow rates in the evaporator. The author also showed that not only the $\mathrm{COP}_{1}$ but also $\dot{Q}_{\text {cond }}$ depends on the flow rate and that the flow rate that maximizes $\dot{Q}_{\text {cond }}$ is not the same as the one maximizing $\mathrm{COP}_{2}$. The simplified optimal solution shows good agreement with detailed simulations of the heat pump system.

The optimal HCF flow rate has also been investigated using simulation tools. Iolova and Bernier (2006) performed a simulation-based comparative study for a school in TRNSYS between a GSHP system using a variable speed drive (VSD) pump and one using constant flow rate. The system is composed of several heat pumps connected in parallel to a borefield. In case of the constant flow rate pump, the borefield pump is always on, regardless of whether the heat pump is on or off. In case of the VSD, each heat pump evaporator has a valve that blocks the flow when the heat pump is off. The VSD pump ensures a constant pressure drop over the system. They concluded that the variable flow system saves up to $82 \%$ of the pumping energy use and $18.5 \%$ of the total GSHP system energy use. The fact that inefficient systems with constant flow rate still exist today stresses the need of simple expressions to calculate the optimal HCF flow rate in GSHP systems.

This paper proposes a simplified analytical solution for the optimal HCF flow rate of a GSHP system taking both the borefield and the heat pump into account. The optimal solution is a function of measurable variables and system parameters and data that can easily be obtained from manufacturer data sheets.

Section 2 describes the steady state models used in Section 3 to derive the analytical solution and Section 4 validates the obtained expression with detailed simulation models.

\section{MODEL DESCRIPTION}

Fig. 1 (a) shows the considered system: a ground source heat pump extracts heat from a borefield with average ground temperature $\bar{T}_{b}$. Thermal power $\dot{Q}_{\text {cond }}$ is supplied to a building at a supply temperature $T_{\text {cond,out. }}$ The mass flow rate of the heat carrier fluid (HCF) at the source side is $\dot{m}$, resulting in an inlet and outlet evaporator temperature $T_{e v a, i n}$ and $T_{\text {eva,out }}$. The considered electrical power uses are compressor power $\left(P_{\text {comp }}\right)$ and source circulation pump power $\left(P_{\text {pump }}\right)$. The mass flow rate at the sink side is assumed to be constant. Fig. 1 (c) shows that such a system has an optimal mass flow rate due to the increase of the heat pump COP (see Section 2.1) and the increase of $P_{\text {pump }}$ with $\dot{m}$.

The following sections describe the heat pump model (Section 2.1), the borefield model (Section 2.2) and the pump model (Section 2.3) that were used to derive an analytical solution for the optimal HCF mass flow rate $\dot{m}$.

\subsection{HEAT PUMP MODEL}

A heat pump is a device that converts heat from a low temperature source to heat at a higher temperature, by compressing a refrigerant using a compressor that is typically driven by an electric motor. The refrigerant evaporates in a first heat exchanger (evaporator), which requires heat at a low temperature. This refrigerant is compressed (state 1 in the Ts-diagram Fig. 1, b) to a higher pressure and temperature (state 2). The refrigerant then condenses to a liquid state (state 3 ) while rejecting heat at a higher temperature in the second heat exchanger (condenser). The refrigerant then expands over an expansion valve and enters the evaporator (state 4 ).

The energy efficiency of the heat pump depends on the refrigerant pressure difference between the condenser and the evaporator. The pressure difference is determined by the required temperature difference which depends on both the source and sink temperature and on the mass flow rates. The temperature difference is controlled by the expansion valve. While the exact control method of the valve is typically a 


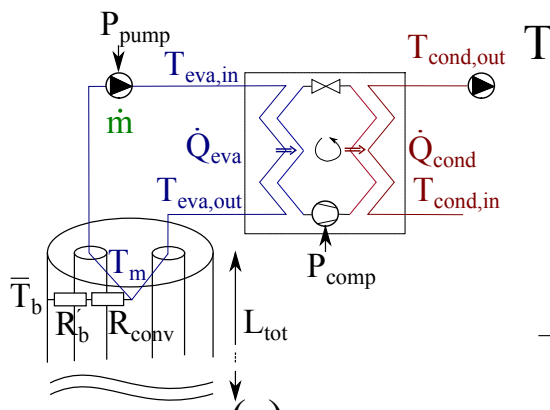

(a)

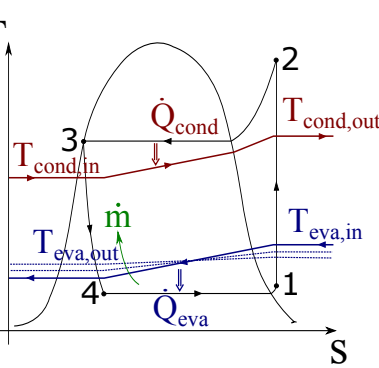

(b)

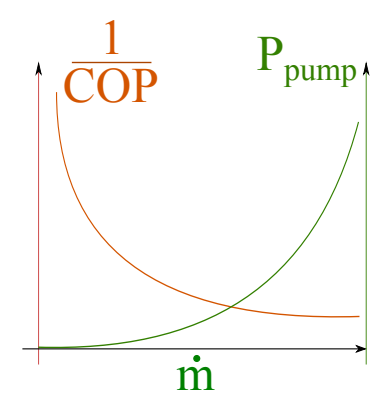

(c)

Figure 1 System description: (a) Schematic description of a ground-source heat pump system, (b) T-s diagram describing the working principle of the heat pump, (c) illustration of the dependency on the $\mathrm{HCF}$ flow rate for the heat pump COP and the pumping power $P_{\text {pump }}$.
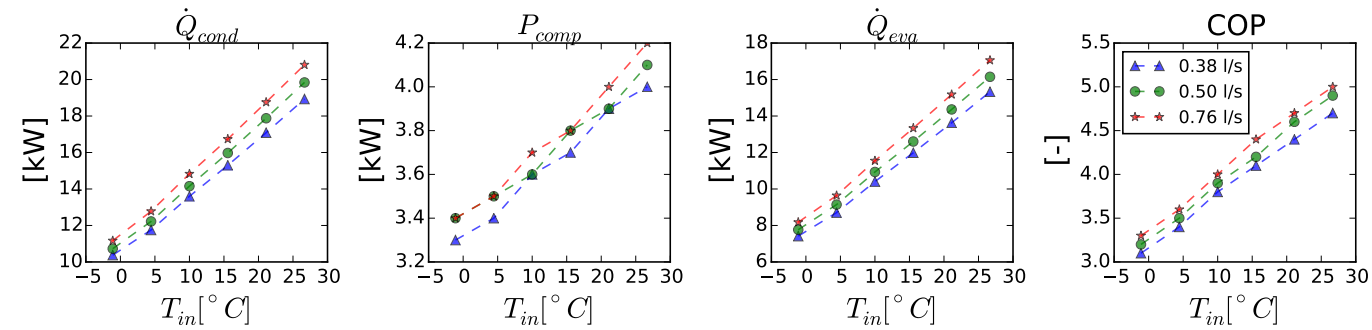

Figure 2 Heat pump characteristics for Carrier ground source heat pump type GZ048 (full load) with $T_{\text {cond,in }}=21.11^{\circ} \mathrm{C}$. Characteristics expressed as a function of $T_{\text {eva,in }}$ and $\dot{m}$.

manufacturer secret, the valve needs to ensure a small amount of superheat in state 1 such that no liquid refrigerant enters the compressor. Furthermore, state 4 should be at a lower temperature than $T_{\text {eva,out }}$ and state 2 should be hotter than $T_{\text {cond,out }}$. These temperatures are further dependent on the HCF flow rate (see blue lines in Fig. 1 (b). Therefore, the HCF mass flow rate $\dot{m}$ in the evaporator indirectly influences the heat pump performance as it changes both $T_{\text {eva,in }}$ and $T_{\text {eva,out }}$.

The heat pump performance data provided by manufacturers are typically the COP and compressor electrical power $P_{\text {comp }}$ as a function of the evaporator inlet temperature $T_{\text {eva,in }}$, the condenser outlet temperature $T_{\text {cond,out }}$ (or inlet $T_{\text {cond,in }}$ ), and (optionally) the evaporator mass flow rate $\dot{m}$. Fig. 2 shows performance data for the Carrier water/air ground source heat pump type GZ048 (full load) for $T_{\text {cond,in }}=$ $21.11^{\circ} \mathrm{C}$ (Carrier, 2016). From Fig. 2 it is clear that the performance depends on both $T_{\text {eva,in }}$ and $\dot{m}$. Based on the discussions in previous paragraphs, a strong relation between $T_{m}=\frac{T_{e v a, o u t}+T_{e v a, \text { in }}}{2}$ and the heat pump performance is expected. The heat pump performance is, however, not provided as a function of $T_{m}$ but it can be computed from the other variables. Transforming Fig. 2 using $T_{m}=T_{e v a, i n}-\frac{\dot{Q}_{e v a}}{2 c_{p} \dot{m}}$, with $c_{p}$ the HCF specific heat capacity, confirms this hypothesis since the curves for the different $\dot{m}$ are now more or less coinciding (see Fig. 3). This relation has been verified for different $T_{\text {cond,in }}$, for Carrier heat pump models G024 to G072 and for Daikin SmartSource 026 (Daikin, 2016).

The steady state behaviour of the heat pump can now be modelled using a linear fit of $P_{\text {comp }}$ and 

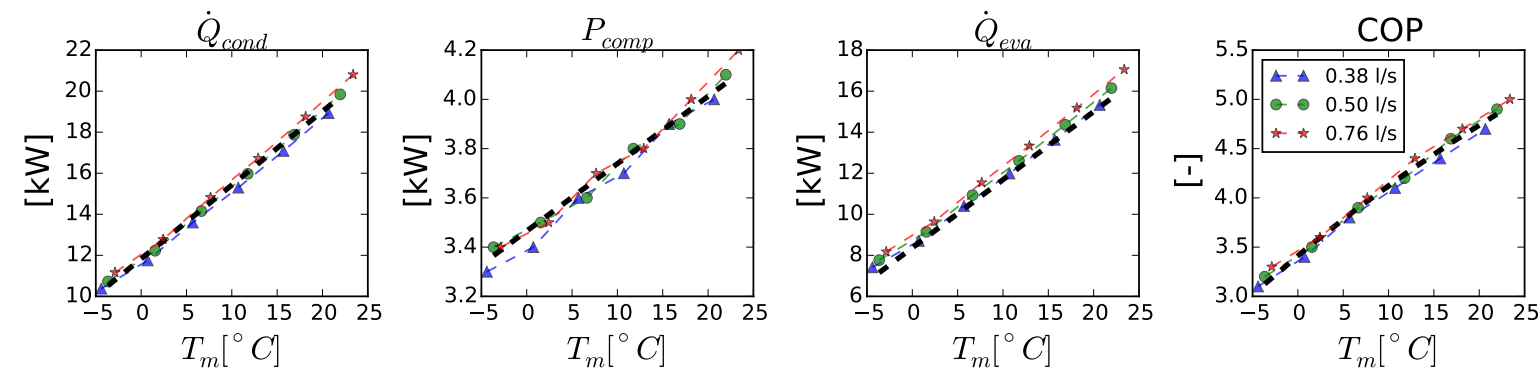

Figure 3 Heat pump characteristics for Carrier ground source heat pump type GZ048 (full load) with $T_{\text {cond,in }}=21.11^{\circ} \mathrm{C}$. Characteristics expressed as a function of $T_{m}$ and $\dot{m}$. For $\dot{Q}_{\text {cond }}$ and $P_{\text {comp }}$, a linear fit is given by the black dashed line. From these two fits, an approximation for $\dot{Q}_{\text {eva }}$ and $C O P$ are deduced.

$\dot{Q}_{\text {eva }}$ (assuming full load and constant condenser inlet temperature):

$$
\begin{aligned}
T_{m} & =\frac{T_{\text {eva }, \text { in }}+T_{\text {eva }, \text { out }}}{2} \\
\dot{Q}_{\text {cond }} & =\alpha+\beta T_{m}, P_{\text {comp }}=\gamma+\psi T_{m} \Rightarrow \dot{Q}_{\text {eva }}=\dot{Q}_{\text {cond }}-P_{\text {comp }}=\alpha-\gamma+(\beta-\psi) T_{m}:=\eta+\epsilon T_{m}
\end{aligned}
$$

\subsection{BOREFIELD MODEL}

A borefield is a heat exchanger in the ground composed of one or multiple boreholes. Boreholes are drilled in the ground to a depth typically between 15 to $180 \mathrm{~m}$ (ASHRAE, 2007) with a diameter between 76 and $178 \mathrm{~mm}$ (Chiasson, 2007). A single U-shaped, double U-shaped or (less frequent) coaxial pipe is inserted in the borehole in order to circulate the heat carrier fluid (HCF). The pipe diameter varies between 20 and $40 \mathrm{~mm}$ (ASHRAE, 2007) and the mass flow rate of the HCF is usually chosen such that the flow is slightly turbulent, or a more conservative flow rate of $0.1 \mathrm{l} / \mathrm{s}$ per pipe may be used. The borehole is filled with grout, which is usually a mixture of bentonite and sand. The grout and the ground thermal conductivities and thermal capacity, as well as the borehole diameter, the pipe arrangement and material and the mass flow rate determine the so-called borehole resistance $R_{b} . R_{b}$ is defined by Hellström (1991) as the thermal resistance per length borehole between the average temperature of the heat carrier fluid $T_{m}$ and the borehole wall temperature $T_{b}$. According to ASHRAE (2007), $R_{b}$ values for single U-pipe range from 0.08 to $0.4 \mathrm{~K} . \mathrm{m} / \mathrm{W}$ but typical values rather range from 0.09 to $0.16 \mathrm{~K} . \mathrm{m} / \mathrm{W}$ for single U-pipe and from 0.05 to $0.08 \mathrm{~K} . \mathrm{m} / \mathrm{W}$ for double U-pipe boreholes (Hellström \& Sanner, 2000).

If the average temperature of the ground at the borehole wall $\bar{T}_{b}$ is known, the most simple borehole model is obtained by disregarding the grout dynamics and by assuming a linear variation of the temperature along the pipe (Lamarche, Kajl, \& Beauchamp, 2010). The ground is assumed to exchange heat $\dot{Q}_{\text {eva }}$ at $T_{m}$. The drawback of this simplification is that $T_{\text {eva,in }}$ (which equals the borefield supply temperature) can become higher than $\bar{T}_{b}$ for low flow rates, which is a violation of the second law of thermodynamics. We therefore assume that $\dot{Q}_{e v a}$ is exchanged with $T_{\text {eva,in }}$ instead. $T_{m}$ can now be expressed as a function of $\dot{m}$ by using the energy balance equation in the borefield:

$$
\begin{aligned}
R_{b}^{*} & :=\frac{R_{b}}{L_{t o t}}:=\frac{R_{b}^{\prime}+R_{\text {conv }}}{L_{\text {tot }}} \\
\dot{Q}_{\text {eva }} R_{b}^{*} & =\bar{T}_{b}-T_{\text {eva }, \text { in }} \\
\dot{Q}_{\text {eva }} & =\dot{m} c_{p}\left(T_{\text {eva }, \text { in }}-T_{\text {eva }, \text { out }}\right) \\
\Leftrightarrow T_{m} & =\bar{T}_{b}-\left(R_{b}^{*}+\frac{1}{2 \dot{m} c_{p}}\right) \dot{Q}_{\text {eva }}
\end{aligned}
$$




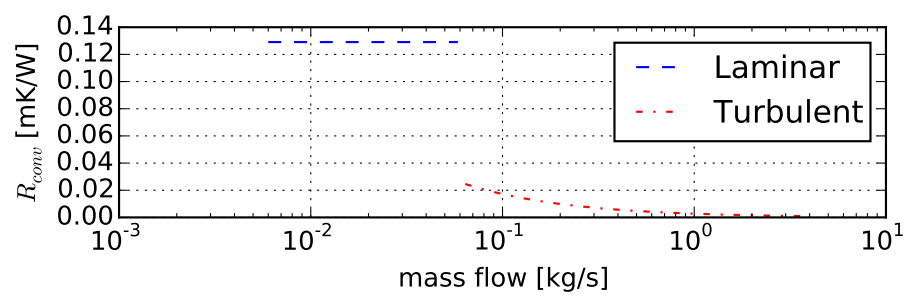

Figure 4 Convective thermal resistance of water in a circular pipe (PN10 32mm).

with the HCF heat capacity $c_{p}$ and the total borehole(s) length $L_{t o t}$. $R_{b}^{\prime}$ is the borehole resistance between the pipe inner wall and borehole wall. The flow dependent convective resistance $R_{\text {conv }}$ is calculated separately. $R_{b}$ is usually obtained experimentally by means of a thermal response test. If the thermal properties of the grout and ground and the exact geometry of the borehole are known, $R_{b}^{\prime}$ can be computed using the multipole method (Hellström, 1991). $R_{c o n v}$ in a circular pipe is computed from Equation $(7)^{2}$ :

$$
R_{\text {conv }}=\frac{1}{\pi \lambda_{f} \mathrm{Nu}} \quad \text { with } \begin{cases}\mathrm{Nu}=0.023 \mathrm{Re}^{0.8} \mathrm{Pr}^{0.35} & \text { if turbulent (Dittus-Boelter correlation) } \\ \mathrm{Nu}=\frac{3.66+4.36}{2} & \text { if laminar (Thirumaleshwar, 2009) }\end{cases}
$$

with the HCF thermal conductivity $\lambda_{f}$, the Reynolds number $\operatorname{Re}=\frac{v_{f} d_{p, i n}}{\nu_{f}}$, the Prandtl number $\operatorname{Pr}=\frac{\nu}{\alpha}$, the HCF velocity $v_{f}$, the inner pipe diameter $d_{p, i n}$, the HCF dynamic viscosity $\nu_{f}$ and thermal diffusivity $\alpha$. Fig. 4 shows that $R_{\text {conv }}$ is only weakly dependent on $\dot{m}$ but that a transition from turbulent to laminar increases the resistivity from about 0.02 to $0.13 \mathrm{~m} . \mathrm{K} / \mathrm{W}$.

\subsection{PRESSURE LOSSES AND CIRCULATION PUMP}

In this section, the circulation pump and typical pressure losses due to the circulation of the HCF in the heat pump and borefield are discussed.

The pressure drop over the heat exchangers depends on the heat pump type and size and can often be found in the manufacturer data sheets. Typically, small units have a pressure drop in the order of $4 \mathrm{kPa}$ at minimal flow $\left(\theta_{\text {eva,max }}:=T_{\text {eva,in }}-T_{\text {eva, out }} \simeq 5 \mathrm{~K}\right)$. Larger units have a pressure drop in the order of $13 \mathrm{kPa}$ at minimal flow $\left(\theta_{\text {eva,max }}=4 \mathrm{~K}\right)$. The pressure losses associated to the borefield happen in the borehole, the horizontal connection pipes, the collector and the various bends, valves and connection elements. Typically, the total pressure drop is in the range of 0.5 to 1 bar, but it can widely vary and detailed pressure drop calculations should be carried out for more accurate results.

A circulation pump has an efficiency $\eta_{\text {pump }}$ that varies between 55 and $85 \%$ at nominal speed (Bernier \& Bourret, 1999), depending on its size. Since the pump load has a quadratic pressure drop characteristic, similarity laws predict that the efficiency is not a function of the pump speed. In this paper we therefore assume $\eta_{\text {pump }}$ to be constant.

Assuming a constant pump efficiency $\eta_{\text {pump }}$ and a cubic relation between pump power and flow rates, and using a certain flow rate $\dot{V}_{0}$ and corresponding pressure drops, $P_{\text {pump }}$ can be expressed as

$$
\begin{aligned}
a_{p} & =\frac{\Delta p_{\text {borefield }}+\Delta p_{\text {heat pump }}}{\eta_{\text {pump }} \dot{V}_{0}^{2}} \\
P_{\text {pump }} & =a_{p}\left(\frac{\dot{m}}{\rho}\right)^{3}
\end{aligned}
$$

with the borefield and the heat pump pressure drops $\Delta p_{\text {borefield }}$ and $\Delta p_{\text {heat pump. }}$

\footnotetext{
${ }^{2}$ For the laminar case, the average value between the correlation for constant heat flux and correlation for constant wall temperature is taken.
} 


\section{OPTIMAL SOLUTION}

In this section, an analytical solution for the optimal HCF mass flow rate is derived by maximizing the system coefficient of performance $\left(\mathrm{COP}_{2}\right)$ (Eq. 10). Constant condenser inlet temperature and full load condition are assumed for the heat pump.

$$
\frac{1}{C O P_{2}}=\frac{P_{\text {pump }}+P_{\text {comp }}}{\dot{Q}_{\text {cond }}}
$$

The optimization problem can be re-written by substituting the model equations in Eq. 10. First $T_{m}$ is obtained as a function of $\dot{m}$ and some parameters using Eq. $2 \& 6$ :

$$
\begin{gathered}
T_{m}=\bar{T}_{b}-\left(R_{b}^{*}+\frac{1}{2 \dot{m} c_{p}}\right)\left(\eta+\epsilon T_{m}\right) \\
\Leftrightarrow T_{m}=\frac{\dot{m}\left(\bar{T}_{b}-R_{b}^{*} \eta\right)-\frac{\eta}{2 c_{p}}}{\dot{m}\left(R_{b}^{*} \epsilon+1\right)+\frac{\epsilon}{2 c_{p}}}:=\frac{\dot{m} \kappa-\lambda}{\dot{m} \xi+\nu}
\end{gathered}
$$

with $\xi:=R_{b}^{*} \epsilon+1, \nu:=\frac{\epsilon}{2 c_{p}}, \kappa:=\bar{T}_{b}-R_{b}^{*} \eta, \lambda:=\frac{\eta}{2 c_{p}}$.

By inserting Eq. $2 \& 9$ in Eq. 10 and developing it with Eq 12, following optimization problem is obtained:

$$
\begin{aligned}
\frac{1}{C O P_{2}}=\frac{\frac{a_{p}}{\rho^{3}} \dot{m}^{3}+\gamma+\psi T_{m}}{\alpha+\beta T_{m}} & =\frac{a_{p} \xi \dot{m}^{4}+a_{p} \nu \dot{m}^{3}+\left(\gamma \rho^{3} \xi+\kappa \psi \rho^{3}\right) \dot{m}+\gamma \nu \rho^{3}-\lambda \psi \rho^{3}}{\rho^{3}((\alpha \xi+\beta \kappa) \dot{m}+\alpha \nu-\beta \lambda)} \\
& =\frac{a_{1} \dot{m}^{4}+a_{2} \dot{m}^{3}+a_{3} \dot{m}+a_{4}}{a_{5} \dot{m}+a_{6}}
\end{aligned}
$$

with $a_{1}=a_{p} \xi, a_{2}=a_{p} \nu, a_{3}=\gamma \rho^{3} \xi+\kappa \psi \rho^{3}, a_{4}=\gamma \nu \rho^{3}-\lambda \psi \rho^{3}, a_{5}=\rho^{3}(\alpha \xi+\beta \kappa), a_{6}=\rho^{3}(\alpha \nu-\beta \lambda)$.

The optimal solution is computed from the roots of the derivative of this function (the denominator is removed from the equation):

$$
\begin{aligned}
0 & =\frac{\partial \frac{1}{C O P_{2}}}{\partial \dot{m}} \\
\Leftrightarrow 0 & =3 a_{1} a_{5} \dot{m}^{4}+\left(4 a_{1} a_{6}+2 a_{2} a_{5}\right) \dot{m}^{3}+3 a_{2} a_{6} \dot{m}^{2}+a_{3} a_{6}-a_{4} a_{5}
\end{aligned}
$$

which becomes after substitution:

$$
\begin{aligned}
0= & 12 a_{p} c_{p}^{2}\left[R_{b}^{* 2} \alpha \epsilon^{2}-R_{b}^{* 2} \beta \epsilon \eta+R_{b}^{*} \bar{T}_{b} \beta \epsilon+2 R_{b}^{*} \alpha \epsilon-R_{b}^{*} \beta \eta+\bar{T}_{b} \beta+\alpha\right] m^{4}+ \\
& 4 a_{p} c_{p}\left[3 R_{b}^{*} \alpha \epsilon^{2}-3 R_{b}^{*} \beta \epsilon \eta+\bar{T}_{b} \beta \epsilon+3 \alpha \epsilon-2 \beta \eta\right] m^{3}+ \\
& 3 a_{p}\left[\alpha \epsilon^{2}-\beta \epsilon \eta\right] m^{2}+ \\
& 2 \rho_{f}^{3} c_{p}\left[\bar{T}_{b} \alpha \epsilon \psi-\bar{T}_{b} \beta \epsilon \gamma+\alpha \eta \psi-\beta \eta \gamma\right]
\end{aligned}
$$

Eq. 17 has possibly 4 solutions $\left(x_{1,2,3,4}\right)$ for the optimal mass flows, which can be computed analytically by solving the root-problem for polynomial $p(x)=a x^{4}+b x^{3}+c x^{2}+e$ :

$$
\begin{aligned}
\Delta & =256 a^{3} e^{3}-128 a^{2} c^{2} e^{2}+144 a b^{2} c e^{2}+16 a c^{4} e-27 b^{4} e^{2}-4 b^{2} c^{3} e \\
p & =\frac{8 a c-3 b^{2}}{8 a^{2}}, \quad q=\frac{b^{3}-4 a b c}{8 a^{3}}, \quad \Delta_{1}=2 c^{3}+27 b^{2} e-72 a c e, \quad \Delta_{0}=c^{2}+12 a e \\
Q & =\sqrt[3]{\frac{\Delta_{1}+\sqrt{-27 \Delta}}{2}}, \quad S=\frac{1}{2} \sqrt{-\frac{2}{3} p+\frac{1}{3 a}\left(Q+\frac{\Delta_{0}}{Q}\right)} \\
x_{1,2} & =\frac{-b}{4 a}-S \pm \frac{1}{2} \sqrt{-4 S^{2}-2 p+\frac{q}{S}} \quad, \quad x_{3,4}=\frac{-b}{4 a}+S \pm \frac{1}{2} \sqrt{-4 S^{2}-2 p-\frac{q}{S}}
\end{aligned}
$$


Table 1 Parameter values used for the validation.

\begin{tabular}{|c|c|c|c|c|c|c|c|}
\hline \multicolumn{3}{|c|}{ Borefield } & \multicolumn{2}{|r|}{ Pump } & \multicolumn{3}{|c|}{ Linear fit } \\
\hline $\bar{T}_{b}$ & 8.7 & {$\left[{ }^{\circ} \mathrm{C}\right]$} & efficiency & 0.675 & $\alpha$ & -83879.5 & [W] \\
\hline$R_{b}$ & 0.085 & {$[\mathrm{mK} / \mathrm{W}]$} & type & Wilo Cronoline-IL 80/220-4/4 & $\beta$ & 350.3 & {$[\mathrm{~W} / \mathrm{K}]$} \\
\hline$R_{\text {conv }}$ & 0.0148 & {$[\mathrm{mK} / \mathrm{W}]$} & $\Delta p_{\text {borefield }}{ }^{*}$ & $170 \quad[\mathrm{kPa}]$ & $\psi$ & 6.7 & [W] \\
\hline$n \times H_{b o r}$ & $99 \times 30$ & {$[\mathrm{~m}]$} & & ${ }^{*_{1}} \dot{m}=14.85 \mathrm{~kg} / \mathrm{s}$ in borefield & $\gamma$ & 1675.0 & {$[\mathrm{~W} / \mathrm{K}]$} \\
\hline$L_{t o t}$ & 329 & [m] & $\Delta p_{\text {heat pump }} *_{2}$ & $27.6 \quad[\mathrm{kPa}]$ & $\eta$ & -85554.5 & [W] \\
\hline$R_{b}^{*}$ & 0.0003 & {$[\mathrm{~K} / \mathrm{W}]$} & & $*_{2} \mathrm{~m}=0.76 \mathrm{~kg} / \mathrm{s}$ in heat pump & $\epsilon$ & 343.7 & {$[\mathrm{~W} / \mathrm{K}]$} \\
\hline \multicolumn{3}{|c|}{ HCF: $20 \%$ glycol } & & Heat pump & & & \\
\hline$\rho$ & 1033 & {$\left[\mathrm{~kg} / \mathrm{m}^{3}\right]$} & type & Carrier - GZ048 & & & \\
\hline$c_{p}$ & 3880 & {$[\mathrm{~J} / \mathrm{kgK}]$} & Characteristics & see Fig. 3 & & & \\
\hline$\nu$ & $2.4 * 10^{-6}$ & {$\left[\mathrm{~m}^{2} / \mathrm{s}\right]$} & $T_{\text {cond,in }}$ & 21.11 & & & \\
\hline$\lambda$ & 0.505 & {$[\mathrm{~W} / \mathrm{mK}]$} & $\dot{m}_{\text {cond }}$ & {$[\mathrm{kg} / \mathrm{s}]$} & & & \\
\hline
\end{tabular}

Even though we cannot prove it formally, we expect the problem to have only one feasible solution. For a practical implementation, the optimal solution can also be obtained by plotting Eq. 13 or by using a line search method to find the roots of Eq. 17.

\section{RESULTS, VALIDATION AND DISCUSSION}

The optimal analytical solution is validated using a simulation model based on an existing GSHP system. The system consists of a borefield with 99 boreholes of $30 \mathrm{~m}$ deep (double U-type), a Wilo Cronoline IL 80/220 4-4 circulation pump, and heat pumps. The total GSHP system pressure drop at nominal flow rate $(14.85 \mathrm{~kg} / \mathrm{s})$ is $170 \mathrm{kPa}$. It is connected to 14 Carrier GZ048 heat pumps that are operated at nominal condenser flow rate with an inlet temperature of $21.1^{\circ} \mathrm{C}$. All parameter values used for the simulation and for the analytical solution are summarized in Table 1 . The system is modelled in Modelica using the borefield model from Picard and Helsen (2014) and the pump model from Wetter et al. (2015). The heat pump model uses a 3 dimensional linear table interpolation of the manufacturer performance data (Carrier, 2016), Fig. 3. The Modelica model is simulated using Dymola 2017.

The parameters used for the analytical solution are summarized in Table 1. The goodness of the linear fits $\dot{Q}_{\text {cond,lin }}$ and $P_{\text {comp,lin }}$ for resp. $\dot{Q}_{\text {cond }}$ and $P_{\text {comp }}$ for the considered heat pump are shown in Fig. 3 (black dashed line). $\dot{Q}_{\text {eva,lin }}$ and $C O P_{\text {lin }}$ are computed from $\dot{Q}_{\text {cond,lin }}$ and $P_{\text {comp,lin. }}$. Fig. 3 shows that $\dot{Q}_{\text {cond,lin }}$ is a good approximation of $\dot{Q}_{\text {cond }}$ but $P_{\text {comp,lin }}$ shows a less linear behaviour. This results in a slight underestimation of $\dot{Q}_{e v a}$ but a good estimation of the COP.

The following experiment is carried out: the borefield is initialised by assuming a uniform ground temperature of $15{ }^{\circ} \mathrm{C}$ and then operating the pump and the heat pump at nominal mass flow rate for 17.4 days. The borefield cools down to around $8.7^{\circ} \mathrm{C}$. The mass flow rate is then changed to a different fixed value (see Fig. 5). Once the heat pump has generated $200 \mathrm{kWh}$ of thermal energy, the COP's are reported. The reason for this approach is to allow objective comparison of a transient system. The analytical solution is obtained by using the same parameter values and a borehole wall temperature of 8.7 ${ }^{\circ} \mathrm{C}$.

Fig. 5 compares the results from the simulation model (blue dashed line) and the analytical model (red dotted line) for different mass flow rates. Fig. 5 (a) and (b) are expressed as a function of the system mass flow rate $\dot{m}_{b f}$ while Fig. 5 (c) and (d) correspond to a single heat pump. Fig. 5 . a shows that the analytical model underestimates the HCF temperatures. This is caused by the assumption that the HCF exchanges heat with the borefield at $T_{\text {eva,in }}$ instead of using an exponential HCF temperature variation (Lamarche et al., 2010). The error gets amplified by the decrease of $\dot{Q}_{\text {cond }}, \dot{Q}_{\text {eva }}$ and $P_{\text {comp }}$ for smaller $T_{m}$ 


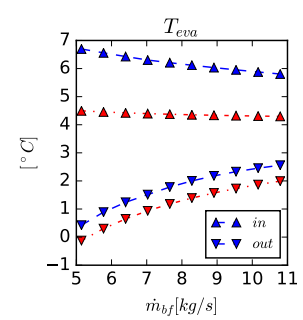

(a)

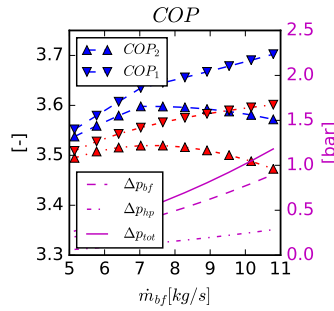

(b)

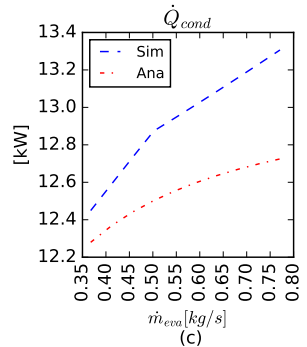

(c)

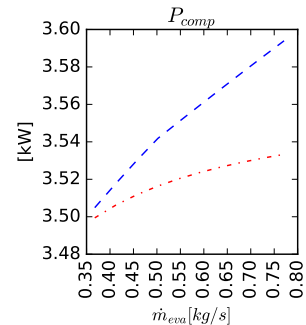

$\dot{m}_{\text {eva }}[\mathrm{kg} / \mathrm{s}]$

Figure 5 Results comparison between analytical model (dotted red) and simulation (dashed blue) model: (a) in and outlet evaporator HCF temperatures; (b) (left axis) heat pump $C O P_{1}$ and system $\mathrm{COP}_{2}$, (right axis) head losses; (c) condenser thermal power; (d) compressor electrical power.

resulting in an underestimation of $C O P_{1}$ (see Fig. 5.b,c,d). Despite this underestimation, the optimal mass flow rate obtained by the analytical solution $(7.38 \mathrm{~kg} / \mathrm{s})$ is close to the optimal mass flow rate obtained from the simulation $(7.03 \mathrm{~kg} / \mathrm{s})$. The optimal mass flow rate is close to (but lower than) the maximum mass flow rate for which heat pump performance data is provided.

It should be noted that optimal $\mathrm{COP}_{2}$ is generally found at lower flow rate as illustrated by Southard, Liu, and Spitler (2014) where the GSHP $\mathrm{COP}_{2}$ was increased by $18 \%$ when the differential pressure set point on the ground loop was reduced from 1.4 to 0.6 bar. The fact that the optimal flow rate for the validation exercise is rather high is explained by its assumptions: i) the heat pumps operate at full load, ii) a relatively small head loss of the ground heat exchanger was used. Running the heat pumps at part load would lead to a lower optimal flow rate as the relative influence of the pumping energy on the $\mathrm{COP}_{2}$ increases. Other assumptions for the validation are i) constant $T_{\text {cond,in }}=21.11^{\circ} \mathrm{C}$, and ii) a cubic relation between pumping power and mass flow rate is assumed.

Further work should experimentally validate the proposed analytical solution for different heat pump load ratio's and different GSHP systems and it should confirm that the optimal flow rate of a GSHP system depends on the heat pump load, the ground temperature, and borefield and heat pump characteristics. Notice that Eq. 2 needs to be re-computed for each heat pump part load ratio as the heat pump characteristics change accordingly. The optimal mass flows can then be derived for each part load ratio.

\section{CONCLUSION}

This paper shows that there exists an optimal heat carrier fluid flow rate for ground source heat pump (GSHP) systems that minimizes its energy use. The paper proposes an analytical solution for computing the optimal flow rate as a function of measurable variables and system parameters and data that can be obtained from manufacturer data sheets. The optimal solution is based on a steady-state approximation of the borehole and a linear approximation of the thermal and electrical power of the heat pump as a function of the average evaporator temperature. It was found that expressing the heat pump powers and COP as a function of the average evaporator temperature instead of its inlet temperature reduces their mass flow rate dependencies. The obtained analytical solution shows good agreement with the optimal solution obtained by a detailed simulation model representing an existing GSHP system of 99x30m boreholes.

\section{ACKNOWLEDGMENTS}

The authors acknowledge the financial support by the Agency for Innovation by Science and Technology in Flanders (IWT) and WTCB in the frame of the IWT-VIS Traject SMART GEOTHERM focusing on integration of thermal energy storage and thermal inertia in geothermal concepts for smart heating and cooling of (medium) large buildings. The authors also acknowledge the financial support by IWT for the PhD work of F. Jorissen (contract number 131012). 


\section{References}

ASHRAE. (2007). AHSRAE Handbook - HVAC Application, Chap 32, Geothermal Energy. American Society of Heating, Refrigerating and Air Conditioning Engineers, Atlanta.

Bernier, M. A., \& Bourret, B. (1999). Pumping energy and variable frequency drives. ASHRAE journal, $41(12), 37-40$.

Carrier. (2016). GZ Infinity Series, Geothermal Split Heat Pump. http://www.utcccs-cdn.com/hvac/ docs/1009/Public/00/GZ-02PD.pdf. ([Online; accessed 12-August-2016])

Chiasson, A. (2007). Simulation and design of hybrid geothermal heat pump systems (Unpublished doctoral dissertation). Dep. Civil and Architectural Engineering, University of Wyoming, Laramie, USA.

Daikin. (2016). Smartsource two-stage horizontal \& vertical water heat pumps, unit size 026-072. http://lit.daikinapplied.com/bizlit/DocumentStorage/WaterSourceHeatPump/ Catalogs/CAT_1114-6_HR_WS_SS_Two_Stage_GTH_GTV_LR.pdf. ([Online; accessed 12-August2016])

Granryd, E. (2010). Analytical expressions for optimum flow rates in evaporators and condensers of heat pumping systems. International Journal of Refrigeration, 33(7), 1211-1220.

Hellström, G. (1991). Ground heat storage: thermal analyses of duct storage systems (theory). Dep. of Mathematical Physics, University of Lund, Sweden.

Hellström, G., \& Sanner, B. (2000). Earth energy designer, user manual, version 2.0 [Computer software manual].

Iolova, N., \& Bernier, M. A. (2006). Quantifying the energy impact of a variable flow pump in a groundcoupled heat pump system. In Conference ESIM 2006 : IBPSA-Canada's 4. Biennial Building Performance Simulation Conference (p. 260-267).

Lamarche, L., Kajl, S., \& Beauchamp, B. (2010). A review of methods to evaluate borehole thermal resistances in geothermal heat-pump systems. Geothermics, 39(2), 187-200.

Li, M., \& Lai, A. C. (2013). Thermodynamic optimization of ground heat exchangers with single u-tube by entropy generation minimization method. Energy Conversion and Management, 65, 133-139.

Nowak, T., Jaganjacova, S., \& Westring, P. (2014). European heat pump market and statistics report 2014. European Heat Pump Association, Brussels.

Picard, D., \& Helsen, L. (2014). A new hybrid model for borefield heat exchangers performance evaluation. ASHRAE Transactions, 120, 1TT.

Southard, L. E., Liu, X., \& Spitler, J. (2014). Performance of hvac systems at ashrae hq. ASHRAE Journal, 56(12), 12.

Thirumaleshwar, M. (2009). Fundamentals of heat and mass transfer. Pearson Education India.

Wetter, M., Fuchs, M., Grozman, P., Helsen, L., Jorissen, F., Lauster, M., .. Thorade, M. (2015). IEA EBC Annex 60 Modelica Library - An International Collaboration to Develop a Free Open-Source Model Library for Buildings and Community Energy Systems. In Proceedings of Building Simulation 2015. Hyderabad, India. 